\title{
Pre-deployment preparation of military nurses of the South African National Defence Force for participation in peace support operations
}

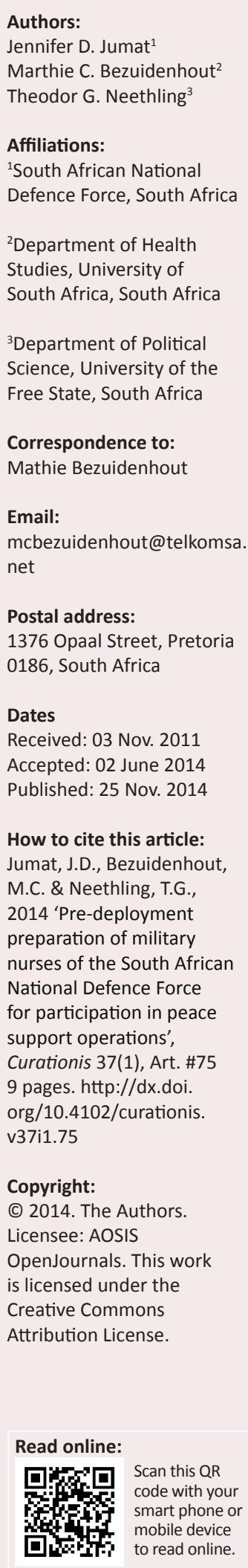

Authors:

Jennifer D. Jumat

${ }^{1}$ South African Nationa

Studies, University of

${ }^{3}$ Department of Political

Science, University of the

Correspondence to:

mcbezuidenhout@telkomsa.

Postal address:

1376 Opaal Street, Pretoria

Dates

Received: 03 Nov, 2011

Accepted: 02 June 2014

ow to cite this article:

M.C. \& Neethling, T.G.,

2014 'Pre-deployment

National Defence Force

for participation in peace

Curationis 37(1), Art. \#75

9 pages. http://dx.doi

org/10.4102/curationis.

Copyright:

(C) 2014. The Authors

Licensee: AOSIS

is licensed under the

Creative Commons

to read online.
Background: South Africa has dedicated itself to participate in peace support operations (PSOs). The concept of 'jointness', involving different arms of services, was adopted within the South African National Defence Force, thus involving nurses in PSOs.

Problem statement: Combat-readiness being a prerequisite for those involved in PSOs raised questions as to the readiness of forces to participate in these missions. There is a need for specific nursing care during PSOs, but the role and functions of nurses during such operations were not clearly defined; thus their preparation for these missions had very little scientific grounding.

Objectives: These were to explore the pre-deployment preparation needs of military professional nurses during PSOs, and to describe the experience of these nurses whilst being deployed.

Method: A quantitative exploratory, descriptive and contextual approach was used. Questionnaires were distributed to 99 professional nurses who had deployment experience, and 72 participated (73\% response rate). Relevant peace mission concepts are the environment, jointness, behaviour and mission readiness, which served as the conceptual bases for the study.

Results: Findings indicated that the nurses were not fully informed of their responsibilities during deployment or the circumstances under which they would have to work and live. Their preparation is not fully integrated with that of the other armed forces, and deficiencies in their training and development were identified which negatively impact on their mission readiness.

Conclusion: Recommendations were made in terms of human resource requirements, psychological training, better integration of jointness training, and content of training and development to ensure mission readiness of nurses.

\section{Introduction}

Given South Africa's commitment to contribute to peace and stability on the African continent, transformation in South Africa and subsequent changes in the South African National Defence Force (SANDF), military professional nurses are now frequently involved in peace support operations (PSOs). These nurses are required to provide health care to peacekeepers working in foreign countries, often in resource-poor environments. Therefore, proper pre-deployment preparation of the nursing contingent is essential to ensure that they are alerted as to what awaits them during their specific deployment session and to provide them with the required knowledge and skills to be effective in their service delivery.

\section{Problem statement}

South Africa is committed to play a meaningful role in contributing to peace and stability on the African continent. Neethling (2000:18-21) predicted that PSOs will be the main future responsibility of the SANDF and emphasised the importance of combat readiness. Bester (2002:215-221) defines combat readiness as the measure to which troops are ready and prepared to participate in PSOs. In studies by Hopperus Buma (1999:107) and Stratford and Collins (1994:142-154) it was found that communicable and infectious diseases, psychological disorders and combat injuries present amongst troops whilst deployed, indicating a need for specific nursing care during PSOs. Furthermore, there appears to be a need amongst those directly involved in peace missions for mission-specific training and mental preparation. A decade ago Heinecken (2002:63) questioned the education, training and developmental aspects relevant to force readiness prior to participating in PSOs. 
It is clear that the involvement of military nurses in PSOs is a relatively new development; however, they have a specific role to play during PSO deployment, must fit into the 'jointness' approach, reach a form of cohesion with the multidisciplinary team, and be equipped to do their required tasks in foreign and often difficult circumstances. Their preparation for optimal functioning is thus imperative. However, limited guidelines exist upon which to base their pre-deployment training and preparation. Hence the need to explore the pre-deployment preparation needs of military professional nurses during PSOs, and to describe the experiences of these nurses whilst deployed. On the basis of this information proactive measures could be taken during the pre-deployment phase to enable these nurses to handle difficult and/or negative aspects better whilst deployed, and to provide them with the knowledge and skills to perform their tasks with confidence.

\section{Aim of the study}

The fact that nurses are deployed as an active component of the PSO team poses the question as to how efficient and effective the current pre-deployment preparation programme is, and what training should be done to ensure optimal functioning of military professional nurses in foreign environments. The aim of this study was to explore the role of military professional nursing personnel in PSOs, and to establish what their preparation for such missions should entail.

\section{Background}

The context of this study is the SANDF, which has undergone considerable transformation since 1994. Nathan (1994:117) states that prior to 1994 the then South African Defence Force (SADF) was known as the most effective fighting force on the sub-continent, and was trained for conventional warfare to fulfil their primary role of protecting the country against external aggression. Their effectiveness was ascribed to high morale, good discipline, excellent training and technological assistance.

In April 1994 the democratic elections in South Africa led to multiple challenges in all spheres of South African life for all of its inhabitants, and also marked the birth of the SANDF. The challenges included processes of transformation and modernisation for the SANDF to stay on par with world trends relating to PSOs (Department of Foreign Affairs 1999).

There is an increased demand for South Africa to contribute to peace and stability on the African continent. Although the SANDF is viewed as being relatively inexperienced with regard to PSOs, it has already participated in various missions since 2001, which have taken place in countries including Burundi, the Democratic Republic of the Congo (DRC) and Sudan (Heinecken 2002:71-74; Neethling 2001:21).

With the joint approach, different arms of the services form part of the multidisciplinary team, and are increasingly starting to train together in order to reach synergy, enhance cohesiveness and, most importantly, build capacity to field a capable and comprehensive force for peace support missions (Neethling 2000:20). Nurses are a relatively new addition to the multidisciplinary team, and therefore ways need to be found to enhance their preparation to ensure mission readiness.

\section{Trends}

According to the White Paper on South African Participation in International Peace Missions (Department of Foreign Affairs 1999), the scope of South African involvement in peace missions can range from broader diplomatic and political initiatives, preventive diplomacy, peace-making and peace-building to those with a more reactive focus, such as observer missions, peace-keeping, peace enforcement and humanitarian assistance.

South Africa would obviously prefer to contribute to those initiatives that aim to address the underlying causes of conflict, and not simply their short-term containment. If South Africa is to fulfil its obligations under the charters of the United Nations (UN) and the Organization of African Unity and the South African Developing Community Treaty in a responsible manner, it must be prepared for the contingencies and requirements of a broad range of peace mission scenarios, and signal this preparedness to the region and international community. This would best be done by creating a pool of high-quality personnel who could be made available for active participation in peace missions through the existing UN Standby Arrangements System, and through information sharing at regional and sub-regional level.

Given the strong preference of the South African Government for contributing to peace-making and peace-building, some form of standby arrangement is necessary for delineating and preparing civilian and civilian police volunteers as well as the military for participation in multi-national peace missions.

\section{Research objectives}

The objectives of the study were to explore the predeployment preparation needs of military professional nurses during PSOs and to describe the experiences of these nurses whilst being deployed.

\section{Definition of key concepts}

The following concepts were used in the study:

- Jointness: This refers to inclusion of all arms of services of the SANDF, other governmental departments and non-governmental organisations in South Africa, in a combined effort to plan and prepare for PSOs in order to achieve shared goals (McIntosh 2003:9-10).

- Military professional nurses: These are trained nurses registered with the South African Nursing Council (SANC) as professional nurses, controlled by the Scope of Practice Regulations of the SANC, who are actively practicing within the domain of the SANDF, wearing distinctive military uniforms and fitting into a structure 
with specific ranks. The term 'nurse/nurses', is used interchangeably with military professional nurses.

- Mission readiness: This refers to the state of readiness achieved by a combat-ready military organisation or part thereof to perform specific missions or tasks as an integral part of a joint or combined taskforce (Neethling 2000:21).

- PSOs: These are multifunctional operations in which impartial military activities are planned to create a secure environment and to facilitate the efforts of civilian elements of the mission to create self-sustaining peace. PSOs may include peace-keeping and peace enforcement, as well as conflict prevention, peace-making, peace-building and humanitarian operations (Wilkenson 2002:27).

\section{Contribution to the field}

Streubert and Carpenter (1999:202) refer to Lusk's (1997) view that 'research topics should be significant, with the potential to illuminate or place a new perspective on current questions.' This applies to this study, since assignment of military professional nurses to PSOs is viewed as a new direction in South Africa, and this avenue needs to be explored. This study generated sound scientific recommendations which can enhance the pre-deployment preparation of nurses as part of a multidisciplinary team.

\section{Conceptual framework}

Due to the lack of recorded research on participation of nurses in PSOs, a conceptual framework was devised using worldview concepts relevant to PSOs. Polit and Beck (2008:141) postulated that 'conceptual models provide a perspective regarding interrelated phenomena, but are more loosely structured than theories.' This study and the data collection instrument were thus based on expert opinion and the following four internationally accepted concepts used in military operations, namely: environment, jointness, behaviour, and mission readiness (Figure 1) (Shamsul Haque 2002:24-26; Nathan 1994:14-15; Armstrong 1995:36; Harmse 1999:12; Booth 1994:335-339). Based on these four concepts, pre-deployment preparation should take place, optimal service delivery during deployment is sought, and retraining takes place should it be necessary:

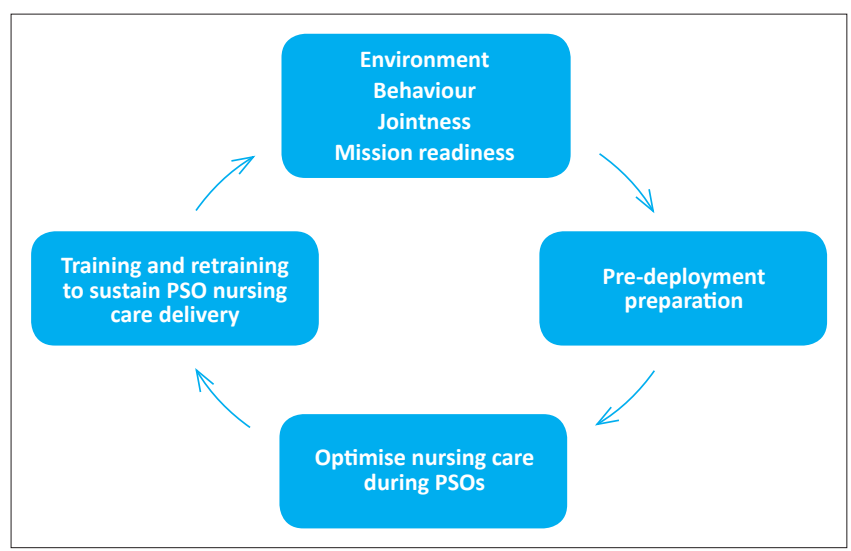

PSOs, peace support operations.

FIGURE 1: The cycle of pre-deployment preparation for PSOs.
- Environment: The environment is the most prominent factor in planning an operation, as it provides the fundamental variables. The Collins English Dictionary (Markins 1991:520) defines the environment as 'external conditions or surroundings, especially those in which people live or work'. Environmental issues and topics, such as climate change, threats to biological systems and energy scarcity, are increasingly discussed at major international forums because environmental disorders often lead to transformer tension (Shamsul Haque 2002:24). As part of the joint system, the South African Medical Health Service (SAMHS) has to plan how nursing care under unusual circumstances can effectively serve the deployed forces.

- Jointness: This refers to the integrated planning, conduct and control of activities where the available resources from more than one service, division, or government department are optimally employed under a unified command to achieve the desired end-state of one nation (McIntosh 2003:10). Jointness is an important factor when optimising nursing care for PSOs as it comprises cohesiveness, cooperation, teamwork, commitment, competencies, capabilities and responsibilities during the planning, preparation and implementation phases of PSOs.

- Behaviour: This is affected by the assignment of nurses to PSOs. They will work in an unfamiliar environment and be sensitive and responsive to given and sometimes unknown circumstances; therefore a change in behaviour is anticipated. Sensitivity to behavioural patterns is required as members adjust to new circumstances. This can be facilitated through preparation, a fundamental tool in optimising military nursing for PSOs (Booth 1994:335, 339; Nathan 1994:118-119). Social and psychological departments evaluate behaviour and apply adaptation tests to determine fitness for deployment.

- Mission readiness: This refers to the state of readiness of the nursing contingency to achieve the organisational objectives. The nursing contingency is expected to contribute to the peace force's capabilities by performing their nursing and healthcare tasks under special or unusual circumstances as an integral part of a joint or combined force.

\section{Literature review}

Very little literature could be found about the role and application of military nurses. Stratford and Collins (1994:143) refer to the history and circumstances of South African military nurses during the period 1914-1994. Samuels and Sommer (1997:73-79) found that a specialised role of community nurses in military humanitarian operations in Guantanamo Bay, Cuba, was to care for displaced persons.

During the South West Africa-Angola war, male operational medical orderlies who were historically and traditionally the 'nursing work force' in South African military institutions 
performed nursing tasks, especially during border duties (Stratford \& Collins 1994:142). Nursing officers who rendered health care during that era were positioned on the borders because their husbands were deployed there for border duty during the war. The war situation no longer exists, but the secondary function of PSOs is more visible than ever, and nursing officers can voluntarily deploy to an area of operation. Previously voluntary deployments were not afforded to nursing officers. The generic function of the nursing officer during peacetime is to care for the uniformed members and their families, but transformation processes enforced by the South African Government in 1994 brought about a shift of emphasis from nursing care under peacetime circumstances to military nursing care in conflict areas.

The White Paper on National Defence for the Republic of South Africa (Department of Defence 1996) and Nathan $(1994: 114,117)$ refer to the functions of the SANDF, emphasising that the primary function is to protect the country against external aggression, whilst the secondary function is to assist in peace-keeping operations, disaster relief, civic action and assistance to neighbouring states.

As a member of the UN, South Africa is committed to contribute to peace operations and post-conflict reconstruction and development of the African continent (Department of International Relations and Cooperation 2011:11). In this regard the SANDF is making a significant effort to maintain peace and security on the African continent, and improvement of humanitarian conditions in conflict-ridden African states. Thus, the SANDF operates in support of political, diplomatic and humanitarian objectives of the broader mission commitment of PSOs, including activities such as separation of combatants, disarmament of irregular forces, demobilisation and transformation of regular and irregular forces into a unified army, assistance with reintegration into civil society, and elections for new governments (Department of Foreign Affairs 1999:13). For these reasons, and the joint approach adopted by the SANDF, nurses are now involved in peace missions.

Lee (2001:3) emphasises the multidisciplinary approach as a means to achieving a holistic view when engaging in PSOs and peace missions. Nursing care is now eminent when the peace force is deployed in conflict areas, as the joint approach in the military environment has led to integration of nursing services into PSOs.

In supportive studies the revised Medical Support Manual for UN Peacekeeping Operations (UN 1999) provides information and is a comprehensive reference for operational and procedural guidelines for medical support. The revised North Atlantic Treaty Organization's (2001) NATO Logistics Handbook introduces the reader to military medical operations.

Turner (1998:170) identifies preparing, arriving, living, working and leaving as deployment trajectories clustered around paradox, leadership, caring, knowing and military variables. Lee (2001:2) is of the opinion that medical support is a key component of military operations other than war, and that nurses need to enhance their skills to better equip themselves for their role during humanitarian assistance. Reineck et al. (2001:931) maintain that it is essential to assemble and evaluate psychometric properties of an instrument to estimate the readiness of nurses for PSOs. At present psychometric tests are implemented prior to deployment to test the peace force members' emotional and social stability to handle the unknown and unpleasant variables during deployment, but more than that is necessary to sufficiently prepare nurses for their deployment role.

\section{Research method and design Research approach and design}

A quantitative exploratory, descriptive and contextual design was used to explore the aspects pertinent to preparation of nurses for deployment during PSOs, based on their experience whilst being deployed.

\section{Population and sampling}

The population constituted 99 registered military nurses working in the SANDF who had been or were currently involved in PSOs in Burundi, the DRC, Sudan and Lesotho. A purposive sampling technique was used to select all of the nurses from the name list provided by the SANDF after consent had been obtained; a census was thus done.

\section{Data collection \\ Data collection instrument}

A questionnaire was used to collect data for this survey. The questionnaire was specifically designed for this quantitative study based on a thorough literature review that focused on demographics, deployment history, pre-deployment preparation, environmental analysis and behavioural aspects. The questionnaire consisted of three sections with 49 fixed-alternative questions. An open-ended question at the end of the questionnaire permitted a more extensive response. The questionnaire was critiqued by experts in the military field and a statistician.

To ensure face validity the questionnaire was designed to include relevant items that universally represented the topic and measured the content relating to nursing involvement and health issues facing nurses during PSOs. The questions were based on knowledge obtained through the literature study, thus ensuring content validity. Academic experts and four senior nurses of the SAMHS were asked to evaluate the instrument for face and content validity.

To enhance the reliability of the questionnaire clear questions appropriate to this study were developed and items were added to serve as cross-references where possible.

Because of the small population of nurses who had deployment experience, the data collection instrument was 
pre-tested with six military administrators and professional nurses who had not been deployed on PSOs, but were known for their sound decision-making skills. Based on their recommendations two new questions were added and the sentence construction was changed in three cases. The pre-test created the opportunity for unplanned personal discussions with two of the participants, resulting in a comprehensive overview of PSOs.

\section{Data collection process}

The researcher submitted the questionnaires plus a name list of the respondents who were deployed at the time of the study to the nodal field post office, from where they were disseminated to the different areas of operation for distribution by the local nursing officer. Respondents who were geographically widespread received their questionnaires via mail, and for those residing in Gauteng province hand-delivery was undertaken by the researcher. A self-addressed and stamped envelope for return purposes was provided in all cases.

Data were collected throughout the nine regions of South Africa and the areas of operation, including Burundi, the DRC and Sudan. Ninety-nine questionnaires were distributed, of which 72 were returned. To acquaint the respondents with the purpose of the study, a covering letter accompanied the instrument. Instructions for completing the questionnaire and the return date were specified.

The respondents were assured that confidentiality and anonymity would be maintained and were instructed not to write their names or any form of identification on the questionnaire; therefore no follow-up of outstanding questionnaires could be carried out.

\section{Data analysis}

A response rate of $73 \%$ was achieved, from which descriptive quantitative data were derived in the form of frequencies and percentages, using the Statistical Package for Social Sciences (SPSS) version 13. The data were presented in tables and graphs.

\section{Results and discussion}

The discussion of research results refers to the data obtained from the 72 self-completed questionnaires. Some questions were unanswered, which is why the total number of responses does not always add up to $100 \%$. The most important results that can influence the predeployment preparation of military professional nurses will be discussed.

\section{Biographical information}

The ages of 71 respondents ranged between 20 and 59 years, with $83 \%$ aged between 30 and 49 years, 75\% female, 56\% either married or living with a partner, $80 \%$ with 6-16 years' experience as a military nurse, and $90 \%$ of 51 respondents who answered this question had completed the Formative Military Course.

Different healthcare practitioners such as nursing and medical officers, operational emergency care practitioners, health orderlies and enrolled nurses were grouped together during deployment.

\section{Environment}

Aspects relevant to the environment were health threats, language barriers, expectations of first deployment, medical waste disposal, standard operating procedures (SOPs) and exposure during deployment.

\section{Health threats}

According to the UN $(1999: 34,61)$ a medical survey of the area indicates the daily workload and possible health threats. Of the nine health threats, the most serious were resistance to malaria prophylaxis $(46 \%)$, maladjustment $(40 \%)$ and hostile action (36\%). However, potential hazards such as landmines, tropical infectious diseases, poor sanitary conditions, sandworms, insect bites and widespread diarrhoea made life uncomfortable for the respondents.

\section{Language barriers}

According to the respondents the most commonly spoken language in the deployment areas was Swahili (69\%), followed by French (14\%). Seventy-nine per cent of the respondents indicated that it was necessary for them to communicate in a foreign language whilst they were deployed, which necessitated working through an interpreter, but there were insufficient interpreters (53\%). Thus, $83 \%$ requested that language skills be included in future training programmes.

\section{Expectations on first deployment}

Although $41 \%$ of the respondents knew what to expect on their first deployment in view of nine stipulated criteria, it is disconcerting to note that a similar number (29 or $40.8 \%$ ) were not aware of their scope of practice, 39\% did not know about the environmental challenges, $44 \%$ did not know about the living conditions, $36 \%$ did not know about their duties and responsibilities, and 31\% did not know about the field facilities. It is thus clear that the expectations of more than $30 \%$ of the respondents were not met on their first external deployment.

\section{Medical waste disposal}

According to the Medical Support Manual for UN Peacekeeping Operations (UN 1999:65, 101) participating countries have shared responsibilities towards waste disposal, proper sanitation and potable water. Special attention must be paid to disposal of biohazardous materials. A waste protocol was available (59\%) and appropriate and safe disposal procedures were followed (50\%), but $27 \%$ of the respondents did not know how the medical waste was disposed off. 


\section{SOPs}

SOPs outline routine and administrative aspects during deployment. With regard to the availability of seven relevant SOPs, the majority of respondents reacted positively that procedures relating to disease prophylaxis $(86 \%)$, casualty treatment $(78 \%)$, evacuation $(75 \%)$, food and water hygiene $(68 \%)$ and waste disposal (52\%) were indeed available. It must be noted that between $14 \%$ and $59 \%$ of the respondents indicated that the listed SOPs were not available, or they were uncertain, illustrating a lack of knowledge in view of procedures which should guide performance of nurses during deployment.

\section{Exposure during deployment}

It is clear that some of the respondents were exposed to negative and/or difficult aspects such as extremely hot weather $(92 \%)$, foreign customs and culture (87\%), insecticides $(63 \%)$, communication breakdown $(66 \%)$, and pests $(65 \%)$.

\section{Jointness}

Jointness is the combination of different aspects to achieve a common military goal. Participation in military exercises for PSOs is normally done to practise skills and prepare the peace force for military operations. A concerted effort should be made to include nurses in these exercises, so that they may acquire skills and qualities relevant to nursing under unusual circumstances, and within the larger team approach. However, participation of the respondents in these exercises was low: $44 \%$ attended once, and only $3 \%$ attended four times, which means practical exposure to simulated circumstances was limited.

\section{Aspects related to deployment}

Considering the number of times the respondents had been deployed, $67 \%$ had been deployed once, $23 \%$ twice, $7 \%$ three times and 3\% four times and more. The duration of deployments varied between one to three months $(73 \%)$, three to six months (23\%) and six months and longer $(4 \%)$. Countries to which the nurses were deployed were the DRC $(63 \%)$, Burundi $(46 \%)$ and Lesotho and Sudan (2\% each). Of the respondents, $96 \%$ provided health care to SANDF members, $43 \%$ to foreign forces and $18 \%$ cared for the local population.

\section{Behaviour}

Factors that influence behaviour negatively affect the service rendering of nursing officers during deployment. One such factor is stress, which can be caused by many different issues.

\section{Stress factors}

Parenthood and making sure their young children were taken care of in their absence was a problem. The main factors contributing to stress during deployment were lack of recreation (89\%), separation from home, family and friends (88\%), difficult and unclear objectives (72\%), not being properly trained for the task $(72 \%)$, the need to suppress one's own emotions (72\%), cultural differences $(72 \%)$, uncomfortable living conditions $(71 \%)$, and change in $\operatorname{diet}(54 \%)$.

In addition to the listed factors, 11 (15\%) respondents indicated internal politics, racism, sexual harassment, incapable commanders, climate conditions, lack of transport, confinement within boundaries and no personal space, insufficient communication with loved ones due to a lack of telephone facilities, lack of equipment, too much money, wine and women, inadequate support from units, abuse of power, double standards in senior officers, victimisation by senior officers, lack of sanitary facilities for females, and the fact that medical task team commanders were non-statutory officers who did not understand health issues as other contributing stress factors. Psychological preparation before deployment was thus essential to maintain a balanced view of their deployment situation (97\%).

\section{Personal skills and qualities}

The respondents strongly identified the following skills and qualities as indispensable to suitable candidates for deployment: good interpersonal and liaison skills (99\%), self-discipline (96\%), professional confidence $(96 \%)$ and emotional stability (94\%).

\section{Mission readiness}

According to Neethling (2000:21) mission readiness is the level of readiness to perform specific missions or tasks as an integral part of a joint or combined force. In this study mission readiness refers to the readiness level of nurses, including their knowledge and clinical competencies, the availability of resources and appropriate training and developmental aspects.

\section{Availability of medication}

Ninety-four per cent of the respondents were satisfied with the available medication, $85 \%$ indicated that the medication was appropriate for the required treatment, and $67 \%$ that the medication was sufficient for the required treatment. It is disconcerting that between $4 \%$ and $29 \%$ of respondents were uncertain about the availability, appropriateness and sufficiency of medication, thus posing a risk to the clients they were treating.

It was noted with concern that $58 \%$ of the respondents indicated that medical supplies were not restocked in time, 29\% that the medical equipment was not suitable for the medical needs of clients, and 36\% that there were no sterilising facilities.

\section{Role and functions of nurses}

Guidelines on how to function are an important element in service provision. A job description was received by $72 \%$ of the respondents, $27 \%$ were not sure whether they received 
one, and $1 \%$ confirmed that a job description was not issued. The lack of job descriptions is a serious limitation in the quest for optimal service delivery and patient care.

\section{Content for pre-deployment programme}

The UN manual (1999:134) lists specific training objectives according to which preparation should be planned and provided. Of the respondents, $99 \%$ indicated that nursing officers who are experienced in PSOs should give inputs in future pre-deployment preparation as they have first-hand experience of the affecting variables.

Table 1 indicates that most of the respondents $(85 \%-97 \%)$, confirmed that the topics listed should be included in a predeployment programme.

Furthermore, $17 \%$ of the respondents indicated other topics that should be included in the pre-deployment programme, namely conflict management, sexually transmitted infections, reproductive health, financial management, sexual behaviour, gender equality, sexual harassment, physical training, foreign languages, and the command and control structure for nurses.

The UN manual (1999:62-63) puts a high premium on preventive medicine and states that it involves every individual in the mission area. Due to a general lack of awareness of malaria amongst peacekeepers, guidelines are provided to control this disease.

Table 2 portrays information about the military health training courses available in preparation for deployment, and indicates a great variation in respondents' pre-deployment attendance of these listed military health training courses.

Completion of some of the most important courses are highlighted: advanced trauma life support $(23 \%)$, advanced cardiac life support (18\%), battlefield advanced trauma life support (48\%), battlefield advanced resuscitation techniques and skills (48\%), biological warfare (33\%), haemorrhagic diseases $(42 \%)$, stress management $(42 \%)$, trauma management $(29 \%)$, theatre training $(13 \%)$ and tropical nursing (10\%). It is evident that more than $50 \%$ of the nurses

TABLE 1: Suggested topics for pre-deployment programme confirmed by the respondents $(n=72)$.

\begin{tabular}{lll}
\hline Topics for pre-deployment & $n$ & $\%$ \\
\hline Health-related problems & 70 & 97.2 \\
Healthcare policies and procedures & 68 & 94.4 \\
Casualty treatment and evacuation & 67 & 93.1 \\
Logistical procedures & 65 & 90.3 \\
Administrative procedures & 68 & 94.4 \\
Prophylactic treatment of various diseases & 66 & 91.7 \\
Management of tropical diseases & 66 & 91.7 \\
Stress management & 67 & 93.1 \\
Occupational health & 66 & 91.7 \\
Management of regional diseases & 61 & 84.7 \\
Health education & 65 & 90.3 \\
Geneva Convention and protocols & 70 & 97.2 \\
Heat exhaustion & 66 & 91.7 \\
Other & 12 & 16.7 \\
\hline
\end{tabular}

were not properly prepared to sustain the health of the peace force during deployment.

Of the respondents $93 \%$ agreed that a training plan should focus on maintaining the standardised core skills and procedures. Because skills and competencies can deteriorate after a period of deployment, these skills and procedures should be standardised and maintained by implementing different levels of repeated training. The UN Medical Support Manual for UN Peacekeeping Operations (1999:3) considers a high state of readiness with regard to timely, responsive and continuous care in a medical system as essential. Of the respondents $90 \%$ agreed with implementation of regular inservice training in order to deploy at any time.

The UN manual (1999:133) emphasises that skills can be lost through professional inactivity, especially on long-standing missions where there is no active armed conflict, or work or environmental hazards. The respondents were asked to indicate whether training and preparation should be coordinated with other arms of services, non-governmental organisations and other governmental departments. In response $70 \%$ of the respondents agreed, whilst $21 \%$ were uncertain and $9 \%$ disagreed that training and preparation should be coordinated with the other arms of service.

Pre-deployment preparation is the most essential aspect of mission readiness. Nevertheless, $44 \%$ of the respondents indicated that they were uncertain about the training and preparation received to do their job during deployment. It is unclear whether the content of the training and preparation was inappropriate or whether they did not attend the said

TABLE 2: Military health training courses completed in preparation for deployment $(n=69)$.

\begin{tabular}{|c|c|c|c|c|c|}
\hline \multirow[t]{2}{*}{ Training courses } & \multirow[t]{2}{*}{$n$} & \multicolumn{2}{|c|}{ Yes } & \multicolumn{2}{|c|}{ No } \\
\hline & & $N$ & $\%$ & $N$ & $\%$ \\
\hline Advanced trauma life support & 62 & 15 & 23.4 & 49 & 76.6 \\
\hline Advanced cardiac life support & 60 & 11 & 18.3 & 49 & 81.7 \\
\hline Aviation nursing & 66 & 39 & 59.1 & 27 & 40.9 \\
\hline Battlefield advanced trauma life support & 69 & 33 & 47.8 & 36 & 52.2 \\
\hline Basic life support & 61 & 24 & 39.3 & 37 & 60.7 \\
\hline $\begin{array}{l}\text { Battlefield advanced resuscitation } \\
\text { techniques and skills }\end{array}$ & 69 & 33 & 47.8 & 36 & 52.2 \\
\hline Biological warfare & 64 & 21 & 32.8 & 42 & 65.6 \\
\hline Combat-readiness training & 68 & 43 & 63.2 & 25 & 36.8 \\
\hline Clinical combat readiness & 68 & 37 & 54.4 & 31 & 45.6 \\
\hline Diagnosis treatment and care & 68 & 46 & 67.6 & 21 & 30.9 \\
\hline Disaster management & 65 & 25 & 38.5 & 40 & 61.5 \\
\hline Emergency care & 65 & 33 & 50.8 & 32 & 49.2 \\
\hline First aid & 66 & 47 & 71.2 & 19 & 28.8 \\
\hline Haemorrhagic diseases & 65 & 27 & 41.5 & 37 & 56.9 \\
\hline Humanitarian assistance & 63 & 17 & 27.0 & 43 & 68.3 \\
\hline Intensive care & 64 & 12 & 18.8 & 52 & 81.3 \\
\hline Malaria treatment & 66 & 42 & 63.6 & 24 & 36.4 \\
\hline Operational readiness & 66 & 30 & 45.5 & 35 & 53.0 \\
\hline Preventive nursing & 65 & 34 & 52.3 & 30 & 46.2 \\
\hline Stress management & 65 & 27 & 41.5 & 38 & 58.5 \\
\hline Trauma management & 65 & 19 & 29.2 & 45 & 69.2 \\
\hline Theatre training & 64 & 8 & 12.5 & 55 & 85.1 \\
\hline Tropical nursing & 63 & 6 & 9.5 & 56 & 88.9 \\
\hline Other & 26 & 6 & 23.1 & 16 & 61.5 \\
\hline
\end{tabular}


training. Although 51\% benefitted from the preparation once they were deployed, 39\% were uncertain about the adequacy of pre-deployment preparation during their deployment.

\section{Ethical considerations}

Permission to access the respondents was granted through the Ethical Committee of the SAMHS and Military Security Department of the SANDF. These two departments are responsible for approval of the research in terms of ethical issues and disclosure of collected information from a military point of view.

As per agreement with the SANDF, the high-security nature of the organisation and sensitive issues that could emerge during data collection and analysis, the researcher acknowledged and adhered to the prescribed etiquette of the Ethical Committee of the SAMHS and the requirements of Military Security with regard to disclosure of information. Due to security breaches and possible access to private online documentation, and to protect the security of the SANDF and the collected data, the researcher chose to send the questionnaires via mail instead of electronic mail, even though the latter would have been less costly and less timeconsuming (Polit \& Hungler 1995:117-129).

In view of ethical principles, the respondents' right to privacy was protected by means of anonymity and confidentiality, their right to fair treatment was based on clear selection criteria, and the knowledge that they may withdraw from the study should they wish to do so and informed consent were achieved by means of an informative covering letter to the questionnaire. This informed them of the study objectives, type of data that would be collected and data collection method (Polit \& Beck 2004:151).

\section{Limitations of the study}

The Ethical Committee of the SAMHS required the proposal and questionnaire to be submitted simultaneously for evaluation prior to approval of this research. This was negatively affected by the strict rule regarding prohibition of the disclosure of information. No official military documents were released for review in terms of prior studies or predeployment preparation.

Over and above the sensitivity about the disclosure of information, the limited research material for this study, in particular within the South African context, made the search for accredited sources extremely difficult. Since this study was the first original study in South Africa which focused on pre-deployment preparation of military professional nurses, no benchmarks were available and therefore all of the health- and nursing-related matters had to be based on general armed force information.

\section{Recommendations}

The findings discussed in this paper generated the following recommendations in view of devising and developing a predeployment preparation programme for nurses.

\section{Environment}

Cilliers $(1995: 59,61)$ states that the credibility of a peace support operation is determined by the capability to accomplish the mission; therefore the following recommendations are made in view of human resources as part of the internal environment:

- Training and expertise in theatre, casualty and intensive care should be planned and implemented proactively.

- Apart from the pre-deployment project resilience workshop, provision should be made for recreational opportunities during deployment to alleviate stress levels.

- The nurse manager should discuss with the nursing officers to be deployed their responsibilities and expectations, thus making sure they understand and accept their job description.

- The nurse manager should make sure that general information about the deployment region or country, such as its population and the circumstances under which they live, the specific conflict situation, role players and danger zones, be conveyed to the deploying nurses.

- Epidemiology in the area of deployment must focus on infectious and non-infectious diseases, acute events, physical, social and psychological problems, so that timely nursing interventions can take place.

- At least a basic knowledge of the relevant foreign language should be acquired before departure.

\section{Jointness}

Jointness is the combination of different aspects and role players to achieve a common military goal:

- The joint approach should be more visible in the field of military operations, allowing nurses the opportunity to practice their skills and apply their theoretical knowledge and practical functional skills as part of the greater team, thus identifying areas for improvement.

- Communication and feedback structures and strategies should be developed and implemented, residing under the SOPs. A combined quarterly or end-of-duty report should be provided to the nursing directorate, which can be used as an information source to detect difficulties and trends in the deployment area.

\section{Behaviour}

Booth (1994:335, 339) is of the opinion that desired behavioural adjustments can be achieved through preparation, which is a fundamental tool in optimising nursing care during PSOs:

- Psychological preparation of nurses should be a priority, thus enabling them to develop psychological and emotional resilience to cope with the many factors and circumstances that present as challenges and cause stress.

- All means of support should be available for the deployed nurses to deal with the repercussions of stress and 
emotional turmoil whilst separated from their normal support systems at home.

\section{Mission readiness}

According to Neethling (2000:21) mission readiness is the level of readiness to perform specific missions or tasks as an integral part of a joint task force. Therefore the following recommendations are made in view of training and development:

- The requirements for deployment (such as the compulsory formative military qualifications) should be communicated in good time and made known to all potential candidates.

- The recruitment and pre-deployment programme should commence at least a year in advance, thus allowing candidates to prepare themselves fully in terms of relevant military, functional, professional and academic qualifications and training.

- The following topics should be included in the predeployment programme:

- The Geneva Convention and Protocols.

- Health care policies and procedures.

- Administrative procedures.

- Prophylactic treatment of various diseases.

- Stress management.

- Occupational health issues .

- Management of regional health-related diseases.

- Health education.

- Heat exhaustion.

- Casualty treatment and evacuation.

\section{Conclusion}

In assessing the pre-deployment preparation needs of military professional nurses in the SANDF by means of the experiences of these nurses, aspects were identified that need greater attention during the preparatory phase of nurses required to serve in neighbouring countries. Challenges were identified which could be managed through proactive planning. Furthermore, a number of topics were identified which should be incorporated into the pre-deployment preparation programme to ensure better informed, adequately equipped and more comfortable individuals. The four concepts of environment, jointness, behaviour and mission readiness grounded the study and were used in a comprehensive and integrated manner.

\section{Acknowledgements}

We wish to thank the SANDF for granting permission for the study to be conducted and to publish this article. Every respondent who completed the questionnaire is thanked for his or her contribution, without which this research project could not be completed.

\section{Competing interests}

No funds were received for this project and the SANDF imposed no limits on the study, except for restricting the release of existing documentation.

\section{Authors' contributions}

J.D.J. (South African National Defence Force) conducted the study for her master's degree, M.C.B. (University of South Africa) was the supervisor and T.G.N. (University of the Free State) the joint supervisor. J.D. obtained permission for the study and collected the data. M.C.B. and T.G.N. guided the research process from its inception until its conclusion. M.C.B. assumed the major responsibility for getting the article written, based on the master's dissertation, and continuing with the process until publication, with inputs from the other authors when requested.

\section{References}

Armstrong, D.A., 1995, 'Jointness and the impact of the war', Joint Force Quarterly (8), 36-37.

Bester, P.C., 2002, 'The conceptualisation of combat readiness for peace-support operations: A South African perspective', International Review of the Armed Forces Medical Services 83(4), 6-8.

Booth, R.Z., 1994, 'A mandate for nursing education leadership: Change', Journal of Professional Nursing 10(6), 335-341. http://dx.doi.org/10.1016/87557223(94)90036-1

Cilliers, J., 1995, 'Peace support operations', Peacekeeping in Africa 2(1), 57-88.

Department of Defence, 1996, White Paper on National Defence for the Republic of South Africa, Government Printer, Pretoria.

Department of Foreign Affairs, 1999, White Paper on South African participation in International Peace Missions (No. 20518), Government Printer, Pretoria.

Department of International Relations and Cooperation, 2011, Strategic Plan: 2011 2013, Government Printer, Pretoria.

Harmse, M., 1999, 'Joint training', Salut 6(2), 12-13.

Heinecken, L., 2002, 'Preparing for operations other than war: how equipped is the SANDF to deal with "soft missions"?', Strategic Review for Southern Africa 24(1) 63-90.

Hopperus Buma, A., 1999, 'Morbidity surveillance among Dutch troops during a peace support operation in Cambodia', Military Medicine 164(2), 107-111.

Lee, S.J., 2001, email, sent on 2 February 2007, research@peaceopertations.org, 'Preparation of family nurse practitioners for their role in humanitarian assistance operations', viewed 03 April 2007 [e-mail to hwharton].

Markins, M., 1991, Collins English Dictionary, 3rd edn., Harper Collins, Glasgow.

McIntosh, S.J., 2003, 'South African National War College: Joint training at the operational level of war', African Armed Forces Journal (2), 9-10, 13-14.

Nathan, L., 1994, The changing of the guard, Human Sciences Research Council, Pretoria.

Neethling, T., 2000, 'Providing combat-ready forces for tomorrow's unexpected challenges', Salut 7(3), 18-21.

Neethling, T. 2001, 'South African engagement in peace missions', SA Soldier 8(4), 20-22.

North Atlantic Treaty Organisation, 2001, NATO Logistics Handbook, North Atlantic Treaty Organisation Office of information and Press, Brussels, Belgium.

Polit, D.F. \& Hungler, B.P., 1995, Nursing research: Principles and methods, 5th edn., Lippincott, Philadelphia.

Polit, D.F. \& Beck, C.T., 2004, Nursing research: principles and methods, 7th edn., Lippincott, Williams \& Wilkins, Philadelphia.

Polit, D.F. \& Beck, C.T., 2008, Nursing research: Principles and methods, 3rd edn., Lippincott, Williams \& Wilkins, Philadelphia.

Reineck, C., Finstuen, K., Connelly, L.M. \& Murdock, P., 2001. 'Army nurse readiness instrument: Psychometric evaluation and field administration', Military Medicine 166(11), 931-939.

Samuels, G.L. \& Sommer, M.D., 1997, 'The role of the community health nurse in military humanitarian operations: Lessons from operation Sea Signal, Guantanamo Bay, Cuba', Journal of Advanced Community Health Nursing 14(2) 73-79. http://dx.doi.org/10.1207/s15327655jchn1402_1

Shamsul Haque, M., 2002, 'Non-traditional security and the environment in Northeast Asia, Work in progress', A Review of Research Activities of the United Nations University 16(3), 24-26.

Stratford, D.O. \& Collins, H.M., 1994, Military nursing in South Africa, 1914-1994, SANDF, Pretoria.

Streubert, H.J. \& Carpenter, D.R., 1999, Qualitative research in nursing: Advancing the humanistic imperative, 2 nd edn., Lippincott, Philadelphia.

Turner, M. D., 1998, The experience of chief nurses in military operations other than war, viewed 16 November 2006, from home.earthlink.net/-turnermh/study

United Nations, 1999, Medical Support Manual for UN Peacekeeping Operations, viewed 12 May 2007, from http://www.un.org/Depts/dpko/training/index.htm

Wilkenson, P., 2002, Peace support operations: A working draft manual for African military practitioners, Institute for Security Studies, Pretoria. 